\title{
EDITORIAL
}

\section{CONTINUING AND BEGINNING}

This is the last issue of The Journal of Psychiatric Education published by Human Sciences Press. This editorial is a companion piece to one in Academic Psychiatry, which continues The Journal of Psychiatric Education with the wider scope implied in the changed title. There is also a change in publishers: from Human Sciences Press to American Psychiatric Press, Inc. (although the latter will not own the journal). The volume numbers progress to show the continuity; Instead of Academic Psychiatry 1(1), it will be 13(1).

These changes parallel those in our sister journal, the Journal of Medical Education, which is now becoming Academic Medicine. We both seem to have been thinking along the same lines: there is much about the overall academic scene that is worth studying and reporting. In this journal's case, additional encouragement comes from the incorporation of the journal in the dues structure of the Association for Academic Psychiatry, which has joined the American Association of Directors of Psychiatric Residency Training in what will be a coownership arrangement of the journal. The combined membership of the associations will guarantee a subscriber base that will pose intellectual rather than financial challenges.

However, the focus will continue to be the education of psychiatrists and the activities of psychiatric educators. In this respect it is appropriate to note that the scope of the journal has been enlarging steadily with encouragement from its readers. We started and continue as the world's only medical specialty educational journal, able to publish well less than half of the articles submitted to us, despite our constant efforts to shorten and catch up. The quality of the material submitted has been reassuringly high over the years and gives every promise of continuing so.

We close with the most important point in this message: our gratitude to Human Sciences Press for their twelve (actually thirteen, considering the start up) years of unflagging support. Norma Fox and Sheldon Roan took on the journal when no one else wanted to, and most thought it couldn't work. They made it work because they believed in what was being reported and that attention ought to be paid to what was happening in psychiatric education. Within three years of the journal's 
start, recruitment into psychiatry bottomed out and has been increasing ever since. The psychiatric educational establishment has grown despite the loss of federal funding, through numerous national, state, and local budget cuts, cost containment efforts, etc. Indeed, that sort of survival and psychiatry's role in reducing medical costs are the sorts of successes that will be covered in the revised journal. But let us pause to note this achievement and the role of Human Sciences in bringing it about.

-Z.T. and R.C. 